\title{
Viagens vividas, pátrias (re)criadas, (re)visitadas em Annemarie Schwarzenbach e Vilém Flusser ${ }^{1}$
}

\author{
Maria de Lurdes Godinho \\ IPPLeiria - ILC
}

Resumo: Numa expressão feliz, o filósofo Bernhard Waldenfels (2007) chama a atenção para uma forma especial de viagem e de apreensão do estranho, quando a viagem conduz ao "estrangeiro interior" [ins innere Ausland] do Eu e o estranho irrompe como algo de extraordinário, eximindo-se às regras existentes. Neste sentido, exige-se, como Foucault acentuara, um "penser du dehors", um pensar que não começa nem acaba em si próprio, mas do "lado de fora" da porta da vida, em demanda de novos caminhos. A esta luz, pretendo discorrer, no meu artigo, sobre a importância que a Viagem (re)vivida, (re)visitada ou imaginada assume na fotojornalista e escritora suíça Annemarie Schwarzenbach (1908-1942), cruzando-a com o papel da Viagem e das pátrias (re)criadas para o filósofo e escritor Vilém Flusser (1920-1991), ambos em demanda de uma pátria interior, através do ato da escrita.

Palavras-chave: Viagem (re)visitada, pátrias (re)criadas, estrangeiro interior, Annemarie Schwarzenbach, Vilém Flusser

Abstract: In a happy expression, the philosopher Bernhard Waldenfels (2007) draws the attention to a special form of travel and of aprehension of the strangeness, when the journey leads to the "inner foreigner" [insinnere Ausland] of the I and the stranger erupts as something extraordinary, exempting the existing rules. In this sense, it is required, as Foucault claimed, a "penser du dehors", a thinking that does not begin or end in itself, but begins "outside" the door of life, demanding new ways. In my article, I intend to discuss on the importance of the re(experienced), (re)visited or imagined travel in the Swiss photojournalist and writer Annemarie Schwarzenbach (1908-1942), by crossing it with the role it plays in the philosopher and writer 
Vilém Flusser (1920-1991), both in search of an inner homeland, through the act of writing.

Keywords: (Re)visited travel, (re)created homelands, inner foreigner, Annemarie Schwarzenbach, Vilém Flusser

Numa expressão que considero feliz, o filósofo Bernhard Waldenfels chama a atenção para uma forma radical de viagem e de apreensão do estranho, quando, face a algo experienciado como extraordinário, a viagem conduz ao "estrangeiro interior" [ins innnere Ausland], começando com contra-experiências que despertam o nosso espanto ou horror, a nossa inibição ou curiosidade e levando a que experiências do estranho irrompam no interior. E adianta:

Brechas e cortes, sem os quais não houvesse a experiência do estranho, nem a experiência de si próprio, são algo mais do que ondas num decurso temporal, que tudo liga num todo: constroem experiências comuns de exterior no interior. 0 estranho como algo de extraordinário, que se exime às regras existentes, exige - para falar como Foucault - um penser du dehors, que não começa em si mesmo, nem acaba em si mesmo. ${ }^{2}$ (Waldenfels 2007: 82)

Assim, num dado fluxo temporal, tanto a autodescoberta como a descoberta do Outro exigem as "contra-experiências" - os cortes e brechas na vida daquele que consegue pensar do "lado de fora", do outro lado da porta da vida, demandando novos caminhos, novos percursos.

Desta forma, não só o espaço exterior possui caráter transitório, de fronteira, mas também os espaços interiores são "lugares de encontro entre culturas, tempos e movimentos viagísticos" e, portanto, fortemente ambivalentes (cf. Karrenbrock 2008: 115). Como exemplificação, basta pensarmos nos protagonistas do volume de contos Bei diesem Regen [Sob esta chuva], da autora suíça Annemarie Schwarzenbach. As figuras presentes nos contos são, essencialmente, exilados, em fuga do nazismo ou do fascismo e de uma Europa no limiar da Segunda Guerra Mundial, o que influencia fortemente a sua própria observação e a avaliação do espaço, bem como a dos narradores/as e, em última instância, 
da autora. Existe sempre uma angústia, uma opressão sobre e entre as figuras que foram expulsas da sua pátria e que, concomitantemente, se sentem "apátridas" [heimatlos], ou ainda "sem chão, sem fundamento" [bodenlos], no dizer de Flusser, o qual especifica o conceito de "Bodenlosigkeit" - muito presente na sua filosofia - como "experiência da solidão" [Erfahrung der Einsamkeit] (1992: 11). Efetivamente, Flusser chama a atenção para o caráter absurdo da "falta de raízes" tanto no reino vegetal/animal - numa planta desenraizada, por exemplo - como no ser humano. E especifica: "sem base razoável (...). Tem-se o sentimento vertiginoso de se pairar sobre um abismo, no qual os conceitos 'verdadeiro' e 'falso' não funcionam” (Flusser 1992: 9-11). ${ }^{3}$

Ao leitor o desenraizamento de todos os protagonistas de Bei diesem Regen, o seu sentimento de "apatricidade", de "Heimatlosigkeit", segundo Flusser (1992: 247) torna-se evidente, visto encontrarem-se em trânsito, num mundo provisório, quase não-existente, em "outros espaços" ou "não-espaços" ("espaces autres", segundo Foucault ou "non-lieux", segundo Marc Augé). Por isso, as ações ou diálogos de uma grande parte dos contos se desenrolam em hotéis, bares, no navio, no automóvel, no comboio (cf. Lehnert 2001: 113). Segundo Foucault, trata-se de heterotopias, que se referem fundamentalmente a lugares com localizações contraditórias. ${ }^{4}$

Por outro lado, os protagonistas percorrem igualmente, muitas vezes, uma viagem "interior", devido a estados febris que perturbam e influenciam fortemente as capacidades de perceção (cf. Godinho 2015: 67). Daí que se possa também falar de uma certa heterotopia "interior" no caso das referidas perturbações da perceção, as quais são provocadas por doenças, ou ainda pelo excesso de drogas e álcool. Devido a isto, cada personagem cria uma outra relação com o espaço. Segundo Vilas-Boas, existe sempre um certo isolamento nas figuras e entre elas, tentando algumas escapar-se-lhe, através das relações que estabelecem com os Outros no "novo" espaço. Que o espaço possa ou não tornar-se heterotopia depende, portanto, da forma como cada figura se relaciona com ele e que função lhe atribui consciente ou inconscientemente (cf. 2010a: 211-212).

Comum às figuras, ao(s) narrador(es) e, em última análise, à autora, é a "experiência da solidão" do exilado (Flusser 1992: 11), o "estar em viagem", em "outros espaços", 
ultrapassando fronteiras, tanto exteriores como interiores (psicológicas), num perpétuo fluir entre a memória, o sonho (advindo das drogas ou álcool) e a vivência crua da realidade, situando-se, portanto, num tempo e espaço híbridos. Assim, os contos de Bei diesem Regen [Sob esta chuva], mostram-nos paradigmaticamente o espaço do "entre", o hibridismo, ou a "hibridez" ou "terceiro espaço de enunciação", segundo Bhabha. Ao explorar esse terceiro espaço, carregado de significado histórico, podemos emergir como os "outros de nós próprios". 5

A título exemplificativo, refira-se o conto "Fast dasselbe Leiden" (BR: 133-140) [Quase a mesma dor], no qual a pintora americana Mrs. Batten diz à eu-narradora acerca da Pérsia:

Die Natur ist hier so stark, dass sie einen tötet. Man müsste aufhören, ein Mensch zu sein, an die menschlichen Bedingungen gebunden. Man müsste ein Stück Wüste und ein Stück Gebirge werden können, und ein Streifen Abendhimmel: Man müsste sich dem Land anvertrauen und darin aufgehen. Dagegen zu leben ist ein solches Wagnis, dass man vor Angst umkommt. (BR: 137) (destacado de AS)

[A Natureza é aqui tão forte que mata qualquer um. Teria de se deixar de ser uma pessoa, de se estar ligado às condições humanas. Teríamos de nos poder transformar num pedaço de deserto e num pedaço de montanha e numa faixa de céu ao poente: teríamos de confiar no país e dissolvermo-nos nele. Viver contra isso é de uma tal ousadia que se perece por medo.]

Como refere Silvia Henke (2008: 145), Mrs. Batten fala aqui como "alter ego" da autora. 0 deixar de ser humano não significa a morte simplesmente, mas o "processo de Sair-de-Si-Mesmo" [Proze $\beta$ des Aus-Sich-Heraustretens], que Henke denomina de "despersonalização" [Entfremdung] ${ }^{6}$ (ibid.). Aqui encontra-se patente a questão da alteridade, ou seja, caminha-se na direção do outro desconhecido, tendo em mente o nosso Eu como estrangeiro interior, tal como Waldenfels o enunciara.

De realçar, contudo, que nestes contos o sentimento de desenraizamento surge no sentido mais estreito, sem a componente positiva presente na filosofia flusseriana. Efetivamente, Vilém Flusser não define a sua teoria de "apatricidade" [Heimatlosigkeit] como algo exclusivamente negativo. Pelo contrário, na autobiografia Bodenlos. Eine 
philosophische Autobiographie [Sem chão. Uma autobiografia filosófica] (vd. Bibliografia), refletindo acerca da sua origem judaica em Praga e do seu próprio exílio, fruto da perseguição nazi, passando primeiro por Londres, estabelecendo-se depois em S. Paulo, e mais tarde, em Robion (França), resume: "Em suma, sou apátrida porque muitíssimas pátrias se armazenam em mim" [Kurz, ich bin heimatlos, weil zu zahlreiche Heimaten in mir lagern] (Flusser 1992: 247). Este texto autobiográfico pode, aliás, entender-se como uma reflexão teórica sobre o seu "pairar" [Schweben] como exilado, sobre os vários lugares em que vai vivendo, num constante "transcender de pátrias", explicando a fuga da sua pátria, Praga, como o mergulhar num nomadismo fecundo (ibid.). Neste âmbito, interessa salientar que Flusser entende que a liberdade do migrante lhe permite, precisamente, a superação das suas pátrias, não rompendo com elas, mas integrando-as: assim, ele próprio se define como praguense, paulense, robionense e judeu, além de se situar dentro do denominado círculo cultural alemão: [Ich bin Prager und Paulistaner und Robionenser und Jude und gehöre dem deutschen sogenannten Kulturkreis an] (cf. Flusser 1992: 252).

Note-se que a interseção entre o exílio e o nomadismo aqui existente só se manifesta porque o exílio é entendido não só numa visão global e exterior, mas igualmente interior ao indivíduo. Segundo creio, na escritora suíça, encontramos o mesmo "pairar" entre pátrias, o mesmo nomadismo fecundo e, posteriormente, a mesma integração e superação das suas pátrias. Mas em Schwarzenbach essa visão global exterior e interior levá-la-á à incessante busca de um espaço e tempo míticos, "pairando" entre espaços e tempos, permeados pela saudade, não só da Suíça natal, mas dos lugares por que passou e amou. Tal é bem visível no artigo "Funchal", de setembro de 1941 (publicado no jornal National Zeitung, a 10.9.41) (AS 2012: 14-16), no qual o idílio bucólico que emprestara à capital lusa, em muitos dos artigos dedicados a Portugal, se estende agora à ilha da Madeira. Encontramos longas descrições entusiásticas, recheadas de imagens eufóricas da ilha da Madeira, num discurso utópico; trata-se, de facto, de um quase "contra-discurso", face aos discursos vigentes na época, acerca da Europa sofredora, revelador de um entusiasmo algo arcádico, pleno de clichés, no entanto perfeitamente compreensível, se tivermos em conta que resume os sentimentos de bonomia e quietude pacífica que a fotojornalista experimentara em Portugal, país este 
arredado da Guerra devastadora que abalava uma Europa sofredora e cinzenta. Através de uma linguagem viva, plástica, ao leitor é transmitida uma visão eufórica:

Kaum am Quai gelandet, begegnete man dem fast unglaublichen Licht violetter Blütenbäume, ganzer Alleen grosser Jacarandas, einer einzigen in der Nachmittagsluft schwebenden Vision, so zart und süss wie Orchideen, und so viel samtene Wärme verbreitend, dass fortan die Mauern und selbst das wie Metall polierte, schwärzliche Pflaster der Gassen wie getränkt mit Violett, diese Farbe betörend auszustrahlen schienen. (...) Und immer erblickte man [...] die helle Fülle von herrlichen Blumen, blühenden Sträuchern, tropischen Früchten und Fuchsien, über wucherten Brunnen und Teichen, die schattige Geborgenheit von Gärten und Höfen, - darüber Loggien, von denen der Blick frei schweift über Dächer, gestufte Gassen, die Fächer von Bananen und Palmen, und Rebenterrasen hinweg bis zum Meer. Es lag jetzt im Abend besänftigt, sein tiefes Blau zerfloss im helleren des Himmels (...). (AS 2012: 14-15) (destacados meus)

[Mal se desembarcou no cais, encontrou-se a luz quase inacreditável de árvores violetas floridas, alamedas inteiras de jacarandás, uma visão pairante no ar da tarde, tão terna e doce como as orquídeas e espalhando tanto calor aveludado, que a partir daí os muros e mesmo o pavimento preto das ruas, polido como metal, pareciam impregnados com violeta, irradiando esta cor encantadora. (...) E avistava-se sempre [...] a abundância brilhante de flores maravilhosas, de arbustos floridos, frutos e fúcsias tropicais, sobre fontes e lagos cobertos por mato, a sombra acolhedora de jardins e pátios, - por cima miradouros, dos quais o olhar deambula livremente por sobre telhados, ruelas com escadarias, ramos de bananeiras e palmeiras e videiras em socalcos à distância até ao mar. Este, agora ao entardecer, estendia-se apaziguado, diluindo o seu azul profundo no mais claro do céu (...)]

Os semas referentes à luz, ao calor, à cor violeta, envolventemente "encantadora", à profusão de plantas, flores e árvores, veiculando a descrição de uma bela paisagem, fotograficamente pormenorizada, com um lindo colorido suave e cálido, concorrem para o inebriar dos sentidos, evocadores do paraíso (terreno), onde não falta a completude da ligação da terra ao mar, numa mescla de azul, no final do excerto.

Em minha opinião, a afinidade entre a descrição do Funchal como jardim lembra o mito de origem do jardim persa de Foucault que considera tal mito "o exemplo mais antigo das heterotopias", por ser gizado tendo em vista a união dos quatro continentes (cf. 
Foucault 1994: 758). ${ }^{7}$ Tanto a Madeira, como Lisboa, em contraste com a Europa sofredora, em Annemarie Schwarzenbach são sentidas/entendidas como o espaço "pátrio" de paz harmoniosa, de unidade humana, uma espécie de jardim-paraíso terreno, evocadoras da grande pátria humanista dos valores europeus. Tal nomadismo fecundo é incompreendido pelos companheiros de exílio, como se pode atentar na seguinte passagem do seu diário africano "Kleines Kongo-Tagebuch I. Abschied von Léopoldville" [Pequeno Diário do Congo I. Despedida de Léopoldville] (publicado no jornal National-Zeitung, a 13.4.42) ${ }^{8}$ (AS 2012: 101-104), que a autora suíça escreveu no então Congo Belga (em Lisala, a 13 de julho de 1941), ao deixar Léopoldville:

(...) wenn ich von so vielen Orten erzähle, die ich schon geliebt habe und von denen mir der Abschied schwer wurde, glaubt man mir nicht. "Heimweh nach Léopoldville?" sagen sie - "Du wirst es schnell vergessen haben!" - Aber so haben sie auch in Kabul geredet, in Baku, in Tallinn, in Teheran, Ankara, Beyrouth, Aleppo, in Lissabon und in vielen anderen Städten. Und ich habe Heimweh nach dem Nebel von Nantucket und den Reben von Kabul und darf nicht daran denken, welche Jahreszeit es jetzt zu Hause ist. (AS 2012: 102-103) (destacados meus)

(...) quando conto acerca de tantos lugares que já amei e dos quais me custou despedir, não acreditam em mim. "Saudades de Léopoldville?" - dizem. - “Tu vais esquecer-te depressa!” Mas também me falaram assim em Cabul, em Baku, em Tallinn, em Teerão, Ancara, Beirute, Aleppo, em Lisboa e em muitas outras cidades. E eu tenho saudades do nevoeiro de Nantucket e das vinhas de Kabul e não posso pensar que estação do ano é agora em casa.]

Aprofundando uma citação de Perret, Vilas-Boas observa (2008: 162) que nos relatos de viagem de Schwarzenbach se encontram muitas vezes expressões de saudade da pátria [Heimweh] que se referem a um tipo específico de memória, a uma necessidade de regresso às raízes onde o indivíduo se sentiu seguro ("com chão", se quisermos usar uma linguagem flusseriana); logo, na autora suíça, aplica-se em primeira instância à Suíça idealizada do passado, da sua infância, aos Alpes e à região de onde a autora provém (especialmente Sils). ${ }^{9}$ Mas, como se vê, o seu nomadismo fecundo leva-a a ultrapassar essa noção tradicional de pátria e a sentir a mesma impressão dolorosa ao deixar os inúmeros 
locais nos vários continentes, que nostalgicamente sente como sua casa, evocadores de uma certa paisagem da sua alma.

A despedida de Léopoldville ${ }^{10}$ causa dor, mas a viagem pelo interior do país é entendida pela fotojornalista como sua missão de vida: conhecer e amar os países e as pessoas, para os poder descrever aos outros. Trata-se de uma alteração naquilo que a autora entendia como sua missão de vida: doravante, fruto do desencantamento político sofrido, não será movida pela luta empenhada, visível nos seus escritos antifascistas, mas a sua missão como repórter consistirá na busca, no conhecimento verdadeiro e amoroso, de lugares e pessoas, para posterior descrição.

No extenso relato autobiográfico "Beim Verlassen Afrikas" [Abandonando África], escrito a bordo do navio português Quanza, na viagem definitiva do então Congo Belga, para Lisboa, entre 14 e 30 de março de 1942 (AS 2012: 123-161), postumamente publicado, a fotojornalista justifica a mencionada viragem na sua atitude, antes ativa, política e socialmente empenhada, para uma reação passiva, introspetiva, como fruto da amargura e descrença sentidas. Esta posição pressuporia o afastamento da civilização branca, remetendo-se ao silêncio (em vez de se procurar defender das calúnias de que seria uma espia nazi), a caminho da busca da essência da palavra e de uma vida espiritual, livre, longe de ódios e desejos de vinganças. ${ }^{11}$

A busca de um novo sentido de vida levou-a a empreender uma longa viagem de barco pelo rio Congo, ${ }^{12}$ no Congo Belga, até Lisala. A partir daí deslocou-se $250 \mathrm{~km}$ pelo interior da selva africana, para visitar uma plantação suíça. Ao fim de um longo percurso pelo interior da selva, a escritora suíça encontra a plantação do casal Vivien, seus conterrâneos, oriundos de Genebra, e a sua chegada assemelha-se a um retorno triunfante à pátria, uma vez que a plantação funciona como "representação arquetípica da criação de cultura e pátria" [archetypische Repräsentation von Kultur- und Heimatgründung] (cf. Decock 2011: 118; Decock/Schaffers 2012: 7):

Heute bezeichnet Molanda nicht mehr eine bescheidene Lichtung, die ringsum von der Macht des Waldes eingeengt und bedroht ist, sondern ein dieser düsteren afrikanischen Wildnis abgerungenes 
Stück Erde, das fruchtbar und bewohnbar ist, wie die Landstriche es sein müssen, damit sie uns zur Heimat werden. (AS 2012: 93)

[Hoje Molanda já não designa uma modesta clareira, concentrada e ameaçada em redor pelo poder da floresta, mas, nesta sombria selva africana, um pedaço de terra recuperado, frutífero e habitável, como as extensões de terra o devem ser, para que se possam tornar a nossa pátria.]

Estamos, de facto, perante uma espécie de paraíso criado no meio da selva africana, onde reina a coexistência cultural pacífica, e se procuram estabelecer os valores ocidentais que conduziram ao desbravar de novas rotas de luz - luz essa entendida no seu sentido físico e no metafórico, como florescimento cultural, ou seja, assiste-se à criação de "uma heterotopia colonial no meio de um mundo ameaçado pela destruição da Segunda Guerra Mundial" (cf. Decock 2011: 118).

A frase: "Fui para as montanhas e escrevi um livro" [Ich ging in die Berge und schrieb ein Buch] (AS 2012: 131) marca o início da nova fase africana de recolhimento introspetivo. Os semas usados remetem-nos claramente para a esfera política quando a autora apelida esse período de "exílio nas montanhas" [Gebirgs-Exil], ou de "exílio no ar mais fresco dos montes e da solidão" [Exil in der frischeren Luft der Berge und der Einsamkeit] (AS 2012: 133).

É nesse exílio (auto)imposto no Baixo Congo que, servindo-se de uma nova linguagem, escreve o "seu" livro, entre outubro de 1941 e fevereiro de 1942. Liberta das peias sociais, a autora suíça, através da sua obra (Das Wunder des Baums [O milagre da árvore]), alcança a Verdade, a Palavra do verdadeiro conhecimento, que claramente nos lembra a revelação de nomes, no Génesis, num processo religioso "milagroso". ${ }^{13}$ Assim, aquele locus amoenus impele-a a usar uma linguagem metafórica, formada pelo par antinómico: "inferno terreno" vs. "paraíso terreno" [irdische Hölle vs. irdisches Paradies], possibilitando-lhe a fuga do "inferno" em que se encontrara nas planícies civilizadas brancas, para atingir o almejado "paraíso terreno", nas montanhas de África, África esta tornada agora sua pátria: 
Ja, dieser Ort in den Bergen des Bas-Congo war mir so etwas wie ein irdisches Paradies geworden, und ich wusste, dass ich Heimweh nach Afrika haben würde. (AS 2012: 137) (destacados meus)

[Sim, este lugar nas montanhas do Baixo-Congo significava para mim algo como um paraíso terreno, e eu sabia que teria saudades de África.]

Em 1942, no derradeiro regresso à Europa, vinda de África, a escassos meses da sua morte, quando pensava anuir à proposta de Henri Martin de se estabelecer em Lisboa, como correspondente de jornais helvéticos, ${ }^{14}$ mostra o seu amor pelo "mundo português", no belo e expressivo artigo "Kleine Reise unter der Flagge Portugals. San Thomé und Madeira, zwei portugiesische Atlantik-Inseln" [Breve Viagem sob a bandeira de Portugal. São Tomé e Madeira, duas ilhas portuguesas do Atlântico] (publicado no jornal Luzerner Tagblatt, a 8.8.1942) (AS 2012: 47-49). Portugal surge aqui como portador da herança cultural europeia, à qual a autora nunca renunciou. Ao avistar Lisboa, emprega a expressiva expressão "heimatliche Europa", que traduzirei pelo enfático duplo substantivo "EuropaPátria":

Ich sah dieses Erbe - das irdische Bild einer selten harmonischen und kühnen nationalen Geschichte und Entwicklung -, als ich jetzt, im dritten Kriegsjahr, aus Afrika in das heimatliche Europa zurückkehrte. Es war eine grosse Reise. (AS 2012: 48) (destacado meu)

[Vi esse legado - a imagem terrena de uma história e desenvolvimento nacionais de rara harmonia e coragem - ao regressar agora à Europa-Pátria, vinda de África, no decurso do terceiro ano de guerra. Foi uma grande viagem.] (AS 2004: 90)

Na sua busca de um tempo e espaços míticos, onde pudesse encontrar a memória europeia humanista apenas lhe surge Portugal, dentro do espaço europeu. No país luso, não só o tempo mas também o espaço parecem estar em suspenso, cercando a autora, em perfeita sintonia com a sua alma. Tal leva-a à construção de uma imagem unilateral e unívoca de um feliz paraíso colorido de Portugal, não se libertando ainda de um certo discurso apologético e ideologicamente conforme ao regime do Estado Novo, na propagação 
de estereótipos acerca do país luso descendente de ilustres Descobridores, e na difusão de imagens de Lisboa, como cidade-luz livre, e dos seus belos arredores como a materialização de idílio bucólico, ou da Madeira como jardim-paraíso.

$\mathrm{Na}$ construção de uma heterotopia colonial e de uma heteroimagem de "euforia mítica"15 de Portugal assiste-se a uma redefinição literária do conceito de "pátria", tal como Friederike Eigler o expôs no seu estudo Critical Approaches to Heimat and the "Spatial Turn" (2012). Partindo da historização do conceito, Eigler entende-o como "manifestação ou imaginação de lugar" que combina as "noções de pertença e identidade com a ligação efetiva a uma região ou um lugar específico" (2012: 27-28). Neste âmbito, distingue entre representações tradicionais e, a partir da Segunda Guerra Mundial, representações alternativas de pátria, seguindo uma nova concetualização advinda com o "Spatial Turn", que introduziam elementos como a subjetividade, o dinamismo e o hibridismo cultural no conceito de pátria. Eigler defende que a pátria já não oferece um lugar estável e natural que conduza linearmente à formação da identidade do indivíduo, encontrando-se esse conceito em permanente mutação e arrrastando o próprio indivíduo na sua transversalidade cultural. (cf. Eigler 2012: 40-48).

Aprofundando a dinamização dos conceitos de espaço e de pátria proposta por Eigler, Peter Blickle (2012) reconhece que a pátria contém uma base territorial, mas não identificável com o lugar de proveniência dos indivíduos nem sequer com um qualquer espaço concreto, antes se devendo estender o conceito a pessoas, sentimentos e conceções de vida:

Everything and nothing may represent Heimat and self and home - different languages, different traditions, different cultures, diffferent countries, different genders (...). The new models [of Heimat, LG] (...) add layers, expand logic, and work with the possibility of multiple simultaneous truths, spaces, times and identities. (Blickle 2012: 44-46)

Para a minha análise, tal hibridismo cultural e dinamismo de conceitos parecem-me muito importantes, visto que neles entram elementos como a possibilidade de construção de várias pátrias pelo ato de escrita, a ideia de mobilidade como possível pátria, ou ainda a possibilidade de, nesse conceito de pátria, coabitarem múltiplos espaços, tempos e identidades. 


\section{Conclusão:}

Em minha opinião, tanto Vilém Flusser como Annemarie Schwarzenbach apresentam uma dinamização do conceito de pátria, por um lado, ao construírem um lugar de pátria seja nos espaços em que residem (como no caso do filósofo judeu), seja nos espaços que percorrem em viagem (como na autora suíça), sentindo uma ligação efetiva e afetiva a lugares específicos, como se, através de um processo identitário, lhes pertencessem. Nesta nova representação do conceito, ativa a partir da Segunda Guerra Mundial, como disse, entram elementos como o dinamismo, a subjetividade e o hibridismo cultural, encerrando este último elemento, para além da possibilidade de construção de várias pátrias, a ideia de mobilidade em si, advinda com a Viagem, como possível pátria (cf. Decock/Schaffers 2012: 8; 18).

Também Edward W. Said, em Reflexões sobre o exílio - referindo-se tanto à obraprima Minima Moralia, como à autobiografia escrita entre 1944-47, de Theodor W. Adorno (em exílio nos Estados Unidos) -, salienta que as reflexões do filósofo e crítico judeu alemão exilado são "animadas pela crença de que o único lar realmente disponível agora, embora frágil e vulnerável, está na escrita”. Como consequência, Said propõe uma teoria de exílio moderna, tendo em conta a figura do intelectual em trânsito, nas suas inúmeras deslocações que exprimem as movimentações da própria contemporaneidade (Said 2003: 57-58), reveladoras de uma "multiplicidade de visão":

A maioria das pessoas tem consciência de uma cultura, um cenário, um país; os exilados têm consciência de pelo menos dois desses aspetos, e essa pluralidade de visão dá origem a uma consciência de dimensões simultâneas, uma consciência que - para tomar emprestada uma palavra da música - é contrapontística. (idem: 59)

Corroborando tal ideia, defendo que em Annemarie Schwarzenbach e em Vilém Flusser, ambos nómadas da palavra, o próprio ato de escrita surge investido de um novo significado, ao funcionar como representação alternativa/moderna ao conceito tradicional e estático de pátria, na medida em que, no exílio (seja autoimposto ou não), literariamente procedem à construção de várias pátrias e pontes linguísticas e culturais. Saindo da "Heimat" limitadora, defrontando e confrontando(-se) com qualquer fronteira, adquirem 
uma pluralidade de visão e a consciência das dimensões simultâneas de que falava Said, adquirindo o papel ímpar de mediadores culturais, construtores do futuro, como demonstra a seguinte citação do próprio Flusser (1992: 249):

Nós, os incontáveis milhões de migrantes (sejamos trabalhadores estrangeiros, exilados, fugitivos, ou intelectuais (...)), reconhecemo-nos não como marginalizados, mas antes como vanguardas do futuro.

\section{Bibliografia}

Bhabha, Homi K (1994). The Location of Culture, London/New York: Routledge.

Blickle, Peter (2012). "Der neue Heimatbegriff”. In F. Grucza (Hg.). Vielheit und Einheit der Germanistik welweit. Frankfurt a. M.: Lang, pp. 41-46.

Decock, Sofie (2011). “The Loving Conquest and Embrace': On Peaceful Heterotopias and Utopias in Annemarie Schwarzenbach's Asian and African Travel Writings". In Women in German Yearbook, vol. 27: University of Nebraska Press, pp. 109-130.

Decock, Sofie/ Uta Schaffers (2012). "Die Suche nach bergenden Räumen als Reise und Schreibprogramm. Annemarie Schwarzenbachs journalistische Afrika-Texte". In Orbis Literatum 67: 1. Blackwell Publishing Ltd, pp. 1-24.

Eigler, Friederike (2012) “Critical Approaches to Heimat and the 'Spatial Turn'”. In New German Critique (2012) 39 (115), pp. 27-48. 
Flusser, Vilém. (1992). Bodenlos. Eine philosophische Autobiographie. Düsseldorf; Bensheim: Bollmann.

Foucault, Michel (2005). De outros espaços. Trad. Pedro Moura. (Acedido a 20.01.2011) www.virose.pt/vector/periferia/foucault pt.html.

-- (1994). "Des espaces autres". Dits et écrits 1954-1988. Édition de Daniel Daniel Defert/François Ewald, e Jacques Lagrange. Paris: Gallimard. 4 vols.

Godinho, Maria de Lurdes das Neves (2015). "Da identidade do exilado durante o Nazismo na Europa: o 'transcender de pátrias' e o 'nomadismo'. Espaço e memória híbridos em Annemarie Schwarzenbach". In Lydia Schmuck/Marina Corrêa (Hg./Eds.) Europa im Spiegel von Migration und Exil. Europa no contexto de migração e exílio. Berlin: Frank \& Timme, pp. 61-87.

Henke, Silvia (2008). "Wie von Asche bedeckt'. Annemarie Schwarzenbachs Prosa zwischen Fremde und Entfernung". In Walter Fähnders/Sabine Rohlf (Hg.) Annemarie Schwarzenbach. Analysen und Erstdrucke. Bielefeld: Aisthesis Verlag, pp. 139-152.

Karrenbrock, Helga (2008). “Nomadische Bewegung. Annemarie Schwarzenbachs Falkenkäfig." In Walter Fähnders/Sabine Rohlf (Hg.) Annemarie Schwarzenbach. Analysen und Erstdrucke. Bielefeld: Aisthesis Verlag, pp. 99-121.

Lavizzari, Alexandra (2008). Fast eine Liebe. Annemarie Schwarzenbach und Carson McCullers. Berlin: edition ebersbach.

Lehnert, Katrin (2001). "Die Darstellung der Fremde in der Prosa Annemarie Schwarzenbachs am Beispiel der Lyrischen Novelle, des Glücklichen Tals und der Novellensammlung Bei diesem Regen". In Elvira Willems Annemarie Schwarzenbach. Autorin - Reisende - Fotografin. Dokumentation des Annemarie Schwarzenbach Symposiums in Sils/Engadin vom 25. bis 28. Juni 1998. Herbolzheim: Centaurus Verlag, pp. 107-118.

Lourenço, Eduardo (1994). Nós e a Europa ou as duas razões, temas portugueses. Lisboa: Imprensa Nacional-Casa da Moeda. 
Perret, Roger (2005). “Nachwort: 'Im Netz der Schicksalswege' Annemarie Schwarzenbach im Banne von Familie, Flucht und Politik". In Annemarie Schwarzenbach, Insel Europa. Reportagen und Feuilletons 1930-1942. Basel: Lenos Verlag, pp. 277-287.

Said, Edward W. (2003). Reflexões sobre o exílio e outros ensaios, trad. Pedro Maia Soares, São Paulo: Companhia das Letras, pp. 46-60.

Schwarzenbach, Annemarie (2012). Afrikanische Schriften. Reportagen - Lyrik. Autobiographisches. Mit dem Erstdruck von "Marc". In Sofie Decock, Walter Fähnders, Uta Schaffers (Hg.), Zürich: Chronos Verlag.

-- (2004). Annemarie Schwarzenbach em Portugal (1941, 1942). Textos de Annemarie Schwarzenbach sobre Portugal. In Gonçalo Vilas-Boas (Introd./Coord.) trad. Maria Antónia Amarante, cadernos do cieg, no 11. Coimbra: CIEG, pp. 89-91.

-- (1998). "Wir werden es schon zuwege bringen, das Leben". Annemarie Schwarzenbach an Erika und Klaus Mann. Briefe 1930-1942. In Uta Fleischmann (Hg.) Mit Beiträgen von Irmela von der Lühe und Fredric Kroll. Pfaffenweiler: Centaurus.

-- (1990). Auf der Schattenseite. Hrsg. v. Regina Dieterle/Roger Perret. Basel: Lenos Verlag.

-- (1989). Bei diesem Regen. Erzählungen. Hrsg. und mit einem Nachwort versehen von Roger Perret. Basel: Lenos Verlag.

Vilas-Boas, Gonçalo (2010a). "Heterotopias na escrita ficcional de Annemarie Schwarzenbach". In Gonçalo Vilas-Boas (Org.) Annemarie Schwarzenbach. Uma viajante pela palavra e pela imagem, Porto: Edições Afrontamento e Instituto de Literatura Comparada Margarida Losa, pp. 207-227.

-- (2010b). “'Et maintenant se fait l'unité entre ce qui parle en moi, et le monde du dehors'. Annemarie Schwarzenbachs Afrika-Texte". In Mirella Carbone (Hg.) Annemarie Schwarzenbach. Werk, Wirkung, Kontext. Akten der Tagung in Sils/Engadin vom 16. bis 19. Oktober 2008. Mit einer Schwarzenbach-Bibliographie 2005-2009. Bielefeld: Aisthesis Verlag, pp. 75-97. 
-- (2008). "Das Wiedererkennen und das Erinnern in den Reisetexten Annemarie Schwarzenbachs". In Sofie Decock/Uta Schaffers (Hg.) inside out. Textorientierte Erkundungen des Werks von Annemarie Schwarzenbach. Bielefeld: Aisthesis Verlag, pp. 153172.

-- (2001). “'Offener Himmel über Lissabon' - Annemarie Schwarzenbach in Portugal” (1941, 1942). In Elvira Willems (Hg.) Annemarie Schwarzenbach. Autorin - Reisende - Fotografin. Dokumentation des Annemarie-Schwarzenbach-Symposiums in Sils/Engadin vom 25. bis 28. Juni 1998. Herbolzheim: Centaurus, pp.169-184.

Waldenfels, Bernhard (2007). “Topographie der Lebenswelt”. In Stephan Günzel (Hg.) Topologie. Zur Raumbeschreibung in den Kultur- und Medienwissenschaften. Bielefeld: Transcript Verlag, pp. 69-84.

\section{NOTAS}

10 presente artigo foi desenvolvido no âmbito do Programa Estratégico Literatura e Fronteiras de Conhecimento - Políticas de Inclusão do Instituto de Literatura Comparada Margarida Losa (UID/ELT/00500/2013 | POCI-01-0145-FEDER-007339).

2 Waldenfels textualmente (2007: 82): "Brüche und Einschnitte, ohne die es keine Fremderfahrung, aber auch keine Selbsterfahrung gäbe, sind alles andere als Wellen in einem Zeitfluss, der alles mit allem verbindet, sie bilden ein Auseinander im Ineinander gemeinsame Erfahrungen. Das Fremde als das Außerordentliche, das sich den bestehenden Ordnungen entzieht, erfordert - mit Michel Foucault zu reden - ein penser du dehors, das weder bei sich selbst beginnt, noch bei sich selbst endet." 
3 No original: "Ohne vernünftige Basis (...). Man hat dabei das schwindelnde Gefühl, über einem Abgrund zu schweben, in dem die Begriffe "wahr" und "falsch" nicht funktionieren" (Flusser 1992: 9-11).

${ }^{4}$ Acerca do conceito das heterotopias, hoje amplamente usado, consulte-se Michel Foucault (1994) [1967]. "Des espaces autres" in: Dits et écrits 1954-1988. Ed. por Daniel Defert/François Ewald, 4 vols. (cf. Bibliografia).

${ }^{5}$ Na sua obra The Location of Culture (1994), Homi K. Bhabha propõe o conceito de "terceiro espaço de enunciação", associando-o ao espaço entre "ver" e "interpretar" (enquanto prática do processo discursivo), ou seja, o conceito de "intersticialidade" ou "in-betweeness" entre significante e significado, no qual se revela o hibridismo, tendo em conta o contexto histórico, social e ideológico do falante (local de enunciação). Bhabha afirma: "It is the in-between space that carries the burden of the meaning of culture, and by exploring this Third Space, we may elude the politics of polarity and emerge as the others of ourselves." (Bhabha 1994: 56).

6 Permito-me usar a tradução "despersonalização" para o conceito "Entfremdung", a partir do outro termo “Depersonalisation", usado paralelamente por Henke neste contexto (cf. 2008: 145).

${ }^{7}$ Acerca do jardim tradicional persa, Foucault afirma textualmente (1994: 759): "Le jardin traditionel des Persans était un espace sacré qui devait reunir à l'intérieur de son rectangle quatre parties représentant les quatre parties du monde, avec un espace plus sacré encore que les autres qui était comme l'ombilic, le nombril du monde en son milieu (c'est lá qu'étaient la vasque et le jet d'eau); et toute la végétation du jardin devait se repartir dans cet espace, dans cette sorte de microcosme."

8 Trata-se no caso do diário africano "Kleines Kongo-Tagebuch" de um relato de quatro partes, o qual foi publicado nos dias 13, 16, 20 de abril e 4 de maio de 1942, no jornal National-Zeitung (cf. Schwarzenbach 2012: 289-290). 0 artigo referido no presente trabalho é o primeiro, publicado a 13.4.1942.

${ }^{9}$ A propósito do sentimento de "Heimweh" para a autora suíça, efetivamente Perret (2005: 277) referira: "Doch das Heimweh, Annemarie Schwarzenbachs treuster "Gefährte" auf allen ihren Reisen, liess sich davon nicht beeindrucken: Es schuf stets friedliche Landschaftsbilder, die an diejenigen ihrer Kindheit in Bocken und Umgebung erinnern." [Contudo, a saudade de casa, o "companheiro" mais fiel de Annemarie Schwarzenbach em todas as suas viagens, não se deixou influenciar por isso: criou sempre imagens de paisagens pacíficas, que lembram as da sua infância em Bocken e arredores.]

10 Por vezes, a fotojornalista suíça escreve "Léopoldville", outras "Leopoldville" e outras ainda "Leo", para se referir à capital do ex-Congo Belga (atual Kinshasa). No entanto, encontrei versões diferentes do mesmo texto: assim, na edição de Decock/Schaffers (cf. 2012: 101-104), agora em análise, surge "Kleines Kongo-Tagebuch: Abschied von Leopoldville", sucedendo-se todas as referências à antiga capital do ex-Congo Belga sem acento, 
enquanto na edição de Auf der Schattenseite (cf. 1990: 303-306), todas as referências a essa cidade mantêm o acento (Léopoldville), mesmo no título.

11 Em carta de 3 de outubro de 1941, Annemarie Schwarzenbach escreve à sua amiga americana Carson McCullers, acerca da sua necessidade de se afastar daquela sociedade "civilizada" e de procurar a sua paz/liberdade interior, alheada da realidade: “(...) ich fühlte in der künstlichen 'Wirklichkeit' des zivilisierten menschlich-gesellschaftlichen Lebens, dass ich in der Tat weit entfernt von der tieferen Wirklichkeit war, vor allem, was meine Seele lieben, verstehen, umfassen will." [(...) sentia, na "realidade" artificial da vida social humana civilizada, que eu, na verdade, estava muito afastada da realidade profunda, em especial daquilo que a minha alma quer amar, compreender e abranger.] (Apud Lavizzari 2008: 116).

12 Vilas-Boas explica que Schwarzenbach se dispôs a subir o rio Congo, na verdade $1.200 \mathrm{~km}$, para visitar o casal suíço Vivien, originário de Genebra, que possuía plantações em Molanda, no coração da Selva (Vilas-Boas 2010b: 83, nota 14).

${ }^{13}$ A aproximação à entidade divina é muito clara se atentarmos na sua correspondência. Assim, numa carta de 18.3.41 a Ella Maillart, a escritora suíça afirma: "And I shall do my best, to keep firm in mind and will, to proceed, to learn, to remember, at any moment and in any situation, that the only real force to make me independent from all outside chance or misfortune, is the force of God and a life in me." (In: Arquivos Literários Suíços, apud Vilas-Boas 2001: 181).

${ }^{14}$ Assim, na última carta, de 2 de setembro de 1942, enviada a Klaus Mann, da sua casa em Sils (Suíça), antes de empreender a planeada viagem para Lisboa, escreve: "In ungefähr sechs Wochen muss ich mich wieder auf den Weg nach Lissabon machen (...)." [Daqui a cerca de seis semanas tenho de me pôr novamente ao caminho para Lisboa (...).] (AS 1998: 189).

${ }^{15}$ Sirvo-me aqui do conceito de "euforia mítica", do filósofo Eduardo Lourenço, aplicando-o à autora suíça, de acordo com a ideia de que, se os Portugueses constroem uma autoimagem eufórica, pelo facto de Portugal haver sido o grande ator dos descobrimentos no passado, essa autoimagem passa para Schwarzenbach como heteroimagem. A esta luz, Portugal surge-lhe como representante da memória e da tradição humanista europeias. 